\title{
Individualized New Teaching Mode for Sports Biomechanics Based on Big Data
}

\author{
https://doi.org/10.3991/ijet.v15i20.17401 \\ Ying Liu ${ }^{(凶)}$, Tengqi Zhu \\ Qufu Normal University, Shandong, China \\ liuying8277@163.com
}

\begin{abstract}
Sports biomechanics is an applied discipline with relatively strong theoretical knowledge. At present, it is used as an analysis means in exercise training in various countries and plays a huge promotion role for the development of competitive sports and sports science. However, phenomena, such as single-teaching methods, fixed-teaching thinking, backward-teaching environment, and hardware, still exist in the current education for sports biomechanics. For such phenomena, we perform individualized IRDC (Internet + retrieval literature + big data + cloud) teaching by using the Internet big data analysis and considering different characteristics of every student and apply it in online teaching of sports biomechanics course. We base our proposed individualized IRDC teaching mode on postmodern curriculum theory. According to four features, namely, rich, recursive, relational, and rigorous, we propose an individualized IRDC online teaching mode in this study. Moreover, we apply a new wireless telemetry surface EMG tester as a learning tool of practical teaching in the teaching mode, which we use to acquire Internet information data of online course and induce a real time communication between teachers and students. Finally, we adopt the principal component analysis to develop evaluation indices, including expert evaluation in and out of school and peer teacher evaluation, for the teaching mode. We find through teaching practice that the proposed individualized IRDC teaching mode can make the best of advantages of big data teaching, help teachers implement targeted individualized teaching, and contribute to the improvement of students' academic performance and comprehensive qualities.
\end{abstract}

Keywords-Smart classroom; interaction; visualization; interaction analysis system.

\section{Introduction}

Currently, sports biomechanics remains an emerging subject based on physics. It aims to apply leading science to systematically study various indices of human physical ability in sports [1]. Sports biomechanics applies complicated motor system in mathematics in the form of dynamics, which can objectively reflect the motor process of human body and facilitate human analysis of biomechanics in sports. With continuous progress of the society, sports biomechanics has become a widely used analysis 
method in exercise training and plays an irreplaceable role for the development of modern sports.

In this era of Internet technology and big data, especially with the outbreak of coronavirus disease 2019 (COVID-19) at the end of 2019, schools utilize all kinds of online teaching platforms for an individualized online teaching mode to continue students' learning [2]. Sports biomechanics is an important PE course. In traditional teaching, teachers usually guide students' movements. Consequently, students know what movements they should perform but fail to understand the reason for these movements. Thus, the traditional teaching mode lacks scientific understanding for students' education. Students train blindly and fail to understand and master training contents and methods [3]. Few class hours, large knowledge quantity, content repetition in some chapters, and lack of practical application also hinder students' learning. The traditional teacher's teaching mode remains an incomplete system and still lacks in terms of interactions with students. The insufficient information quantity of the data cannot reflect the superiority of an individualized online teaching.

Given the above weaknesses of the traditional teaching mode, we propose an individualized IRDC (Internet + retrieval literature + big data + cloud) teaching mode in accordance with the big data technology for sports biomechanics. This study contributes several innovations. First, we apply the IRDC teaching method in the online teaching process of sports biomechanics for the first time and conduct a teacher's assessment of online teaching cognition link. Second, we integrate a targeted individualized teaching method and create an interaction space between teachers and students by using the big data analysis technology. Third, we give full play to the feature of sports biomechanics as a cutting-edge subject and use the wireless surface EMG tester produced by NORAXON in the practice course for the first time. Finally, different from traditional teaching evaluation, we construct an individualized online teaching evaluation in accordance with principal component analysis (PCA). The evaluation system pays attention to the multi-dimensional comprehensive assessment, with the aim of constructing information-based teaching that focuses on foundation, highlights application, and enhances tracking. We hope that our proposed teaching mode can provide a teaching reform reference for biomechanics, physics, and similar subjects and offer suggestions on how to cultivate applied talents.

\section{State of the Art}

Sports biomechanics is an important required course, which deems biomechanics as the key point to analyze the influence of human movements on human body from the perspective of biology and combines theory and practice for movement essentials in sports [4]. At present, sports biomechanics is characterized by the combination of biomechanics knowledge and movements, and teachers can teach it with a flexible teaching method. For example, Singh et al. [5] trained students' problem-solving capability by guiding them to an active, adaptive, and experiential learning in bioengineering teaching. Carpes et al. [6] combined biomechanics course and competition events of Olympic Games for a case-based teaching mode. The project was imple- 
mented in the whole academic semester and involved different activities, which were consistent with the philosophy of Olympic modalities and dedicated to the improvement of teaching-learning process. The project was beneficial to the hidden curriculum in terms of teamwork promotion, personal and group challenges, contact with the local community and other students, and science popularization. Gao et al. [7] proposed that biomechanics should pay attention to the development of experiment teaching materials and conducted teaching reform experiment by using "hurdling" as the teaching case on the basis of information-based electronic textbooks. They found that the experimental class had better performance and higher accuracy of skill mastery than the control group. In the current information age, educators actively explore new teaching modes in sports biomechanics course and especially drive teaching practice through the application of modern information education technology to help some students with poor foundation understand the learning content of the course easily [8]. Lee [9] applied the high-speed camera in biomechanics learning and supported students to participate in the practice of scientific modeling. In teaching, they asked 15 students to use the high-speed camera and stop motion animation software to make the dynamic model of movements and body kinematics. The results indicated an improvement on students' knowledge understanding and application abilities. In recent years, although China's biomechanics education has started later than Western companies, the teaching theory of biomechanics has developed and improved through continuous reform and innovation. Fu et al. [10] put forward the inverse method as the teaching method and stressed learning from observation when teachers explained movements. Students learned through movement reappearance in their minds. The results showed that this teaching method was beneficial to students' accurate biomechanics movement analysis. Sun [11] integrated animation technology in sports biomechanics teaching and guided students to record, play back, analyze, and explain sports movements in the form of sound and image and then compared sound and images of students in each group in a classroom. This method was beneficial for students' profound understanding of their acquired knowledge and improvement of academic performance. However, existing studies on sports biomechanics in China have some deficiencies. For instance, for the mechanics principle in biomechanics course, a mechanical theoretical knowledge teaching mode is adopted in traditional teaching. Thus, students' knowledge mastery degree and their learning interest are low. The teaching method is also single. Teachers need to fix their teaching thinking because it affects students' innovative thinking and separate classroom teaching content from practical knowledge application.

To sum up, the current sports biomechanics teaching mode has some problems, which affect the development of the course research to a degree. Accordingly, we conduct systematic analysis and exploration of the development status of sports biomechanics and then design an individualized IRDC teaching mode suitable for different student features by using the big data technology. We also apply the advanced wireless surface EMG tester in teaching to help students enhance practical experience. We hope that this teaching reform experiment can promote quality effect of biomechanics teaching, improving the overall development quality of sports biomechanics. 


\section{Application of an Individualized IRDC Teaching Mode Based on Big Data}

\subsection{Construction of the proposed individualized online teaching in classroom} activities

He obtained this theory by collecting the advantages of various schools and then applied it in postmodern curriculum theory. In this curriculum theory, he combined the process of practical classroom teaching and proposed the theoretical framework of postmodern curriculum. This theory plays an important promotion and driving role for scholars to explore sports biomechanics course teaching. It is also characterized by $4 \mathrm{R}$, namely, rich, recursive, relational, and rigorous, as shown in Fig. 1.

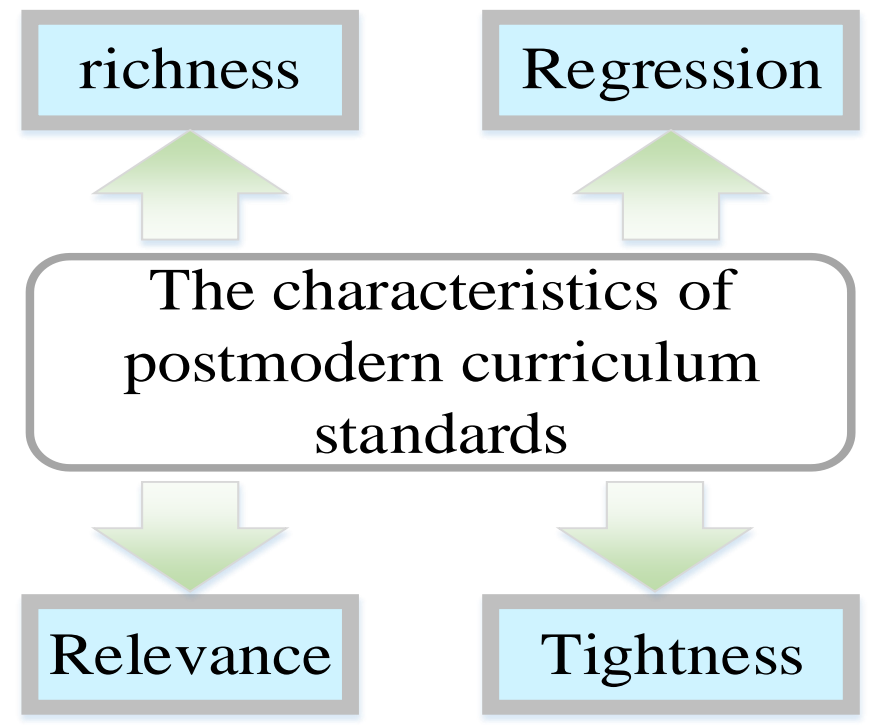

Fig. 1. Characteristics of postmodern curriculum theory

Given the problems of online teaching, such as insufficient individualization and pertinence, inadequate online teaching data collection, lack of wisdom, and inefficient interactions between teachers and students, we construct an individualized IRDC teaching model by using big data, as shown in Fig. 2 . 


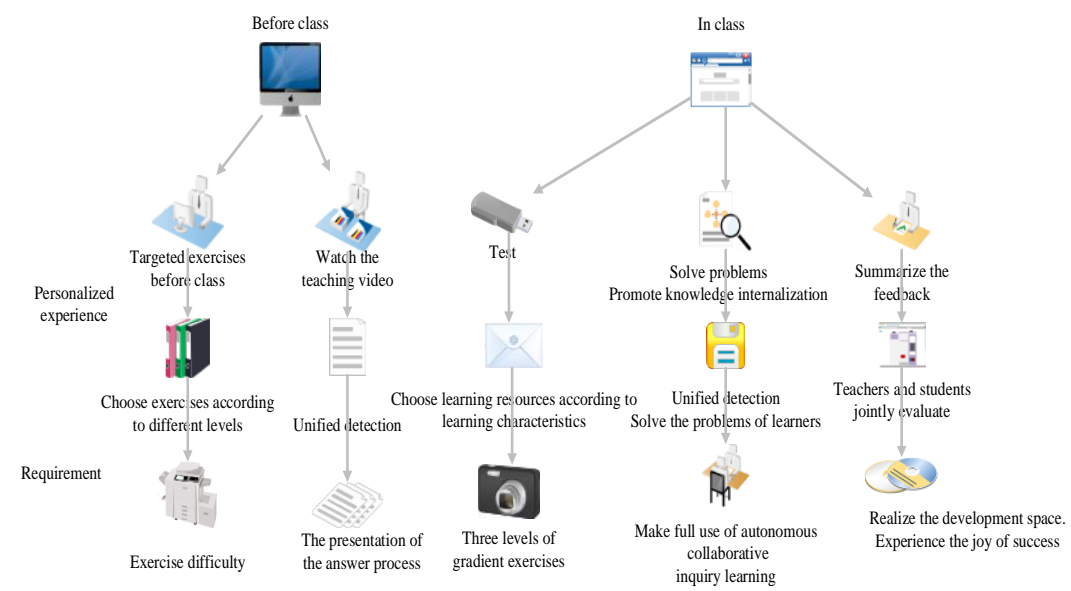

Fig. 2. Construction of an individualized online teaching mode

As shown in Fig. 2, the individualized online teaching mode has high requirements for students' knowledge mastery degree (completion of $80 \%-90 \%$ of evaluation items). Specifically, it requires learners to reflect individualized learning before and during the class. Studies find that students' learning effect differs because of their different mastery levels of pre-class knowledge. Thus, the proposed individualized online teaching advocates sufficient learning time before class and flexible learning methods for students. For example, students with different levels choose different exercises and may select different learning resources. Fig. 2 also reflects that the proposed individualized online teaching emphasizes learning process, which promotes sufficient, free, and harmonious student development through proper methods, means, contents, starting points, process, and evaluation modes considering students' personality characteristics and development potential. Students should have suitable learning contents and materials in their learning process, and teachers should meet their students' personality characteristics as far as possible to improve their learning efficiency and mastery of the learning content.

\subsection{Implementation plan of the IRDC teaching mode in sports biomechanics course}

Given the deficiencies in the current individualized IRDC teaching in terms of individualization, wisdom, and interactivity, we construct an individualized IRDC online teaching mode in this study, as shown in Fig. 3. 


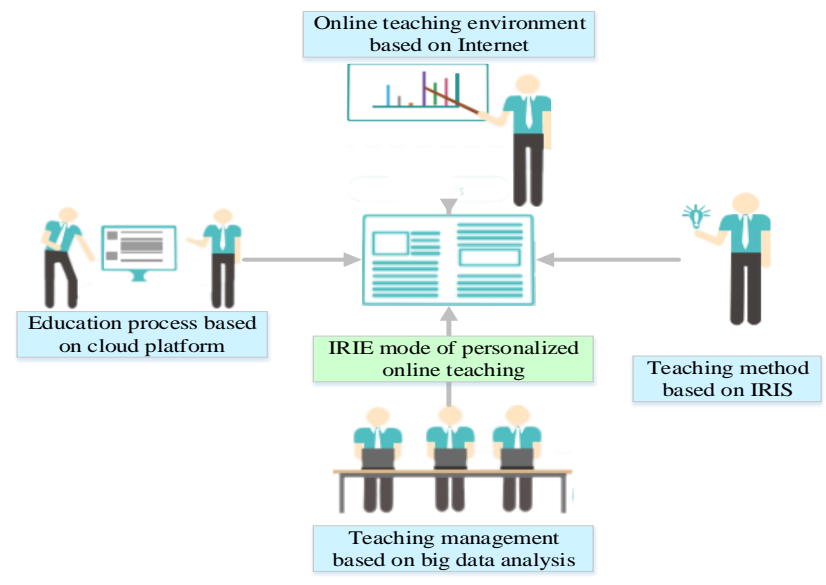

Fig. 3. Frame diagram of the proposed individualized IRDC online teaching process

As shown in Fig. 3, in the proposed individualized IRDC online teaching process, IRDC mode refers to individualized smart teaching model based on "Internet + retrieval literature + big data + cloud": (1) "I" refers to an individualized smart teaching mode based on online smart teaching environment. (2) "R" refers to documentoriented self-learning developed from a problem-based learning teaching method. It focuses on the improvement of students' capacity for scientific research, active learning, and critical thinking skills. (3) " $\mathrm{D}$ " refers to the teaching management and service based on data analysis. It aims to conduct a scientific analysis of multi-dimensional data generated before, during, and after the class for the insufficient intelligence of individualized smart teaching and the system improvement of teaching management and service. (4) "C" refers to cloud-based teaching process. It focuses on the problem of insufficient interactivity in individualized smart teaching and achieves interactive teaching process of individualized teaching through the smart platform.

\subsection{Individualized IRDC teaching mode integrated with new sports biomechanics software}

A wireless telemetry surface EMG tester produced by NORAXON is relatively new software applied in sports biomechanics teaching. NORAXON has initiated signal processing technology internationally and provided clear, coherent, and reliable data for different types of equal length or equal speed training. NORAXON has produced a wireless telemetry surface EMG tester. The software can help students understand and visually view objective data of sports biomechanics. Specifically, it can express movements directly with data to help students study the motion principle and improve the teaching effect. 


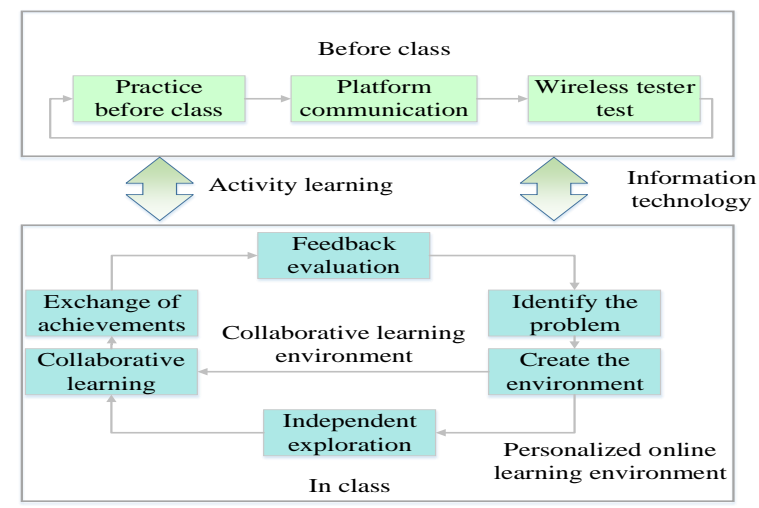

Fig. 4. Individualized IRDC teaching mode

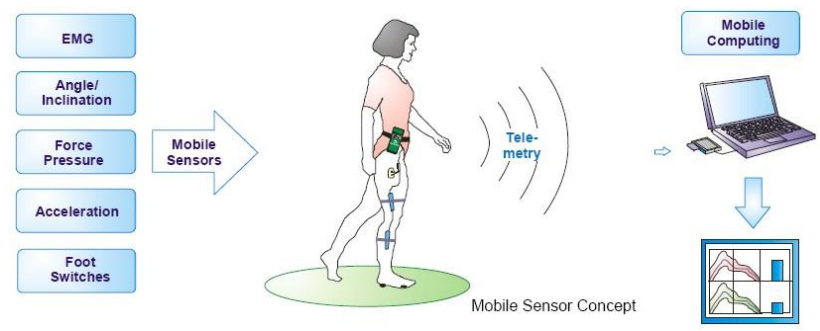

Fig. 5. Application of new sports biomechanics software in the proposed individualized IRDC teaching mode

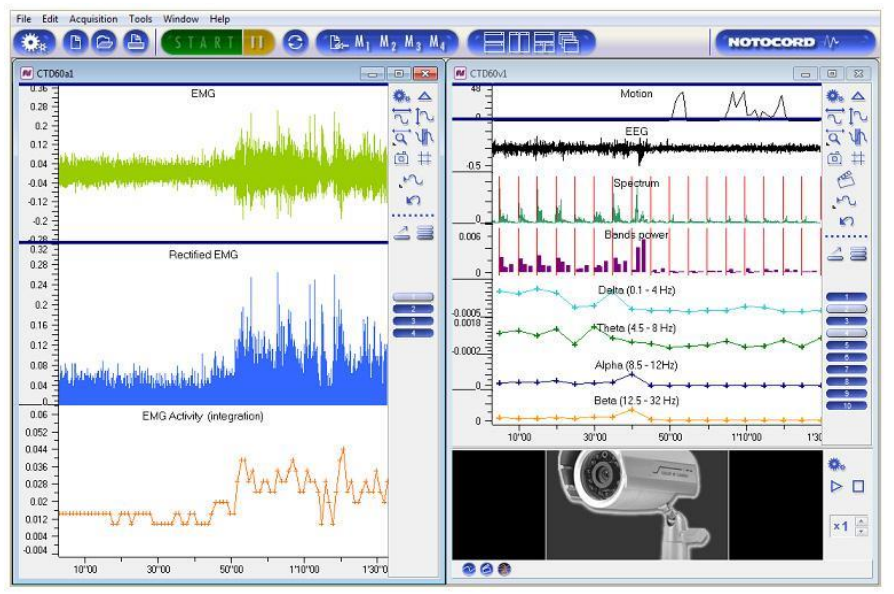

Fig. 6. Analysis of students' muscle analysis assignment in the proposed individualized IRDC teaching mode

This study further expands the current individualized IRDC teaching mode. We design an individualized IRDC teaching process that covers the proposal and solution of 
problems and includes independent thinking and cooperative learning for problems and learning result communication (Fig. 5). Moreover, the proposed individualized IRDC teaching mode also underscores Internet information data acquisition, supply of instant communication platform between teachers and students, and online teaching flexibility. Pre-class step includes application of wireless tester for testing, arrangement of pre-class preview, and online interaction for problems. During the class, teachers can focus on the problems encountered in the pre-class preview and encourage students to solve problems by using the big data of the network platform. Students may cooperate to research. Finally, each group can display their research results, and teachers can evaluate the teaching quality of one another (Fig. 6).

\subsection{Implementation plan of the individualized IRDC teaching mode based on big data in sports biomechanics}

To improve information level of teaching mode by using big data environment: To improve the information level of online teaching mode under the context of big data environment, we integrate college online teaching platform with existing basic information platforms. We also create a data-linked individualized teaching environment. First, this proposed method automatically collects, cleans, and applies data by constructing national basic education database and national-level educational management information system. Second, it conducts system and data interconnection with various educational management information systems and basic databases to screen valid data of teaching quality and student track. Third, it constructs a big data collection and analysis platform. Fourth, it optimizes existing campus information data environment. At present, nationwide information construction has gradually transited to data center construction in accordance with cloud computing from initial network construction and software and hardware purchase, including digital campus building and online learning platform construction. The digital campus application system is an integrated business processing and application system oriented to various schools at each level. It can conduct digital integration and management of all information resources. This system manages massive data about school, teaching, and student cultivation, and thus it is an important data source. Internet access convenience and especially nationwide large-scale online teaching during COVID-19 prevention and control make almost all teachers and students in many colleges and universities leave massive data on various online teaching platforms. Hence, the construction of a network environment for multi-data acquisition and the improvement of automatic data processing and management level are necessary.

To conduct online teaching management and service based on individualized features: According to the needs of five levels: campus management, teaching, service, employment, and scientific research, we construct an individualized online teaching management and service model in accordance with intelligent prediction and machine learning in this study by researching application correlation of campus big data, analyzing data change rules-based time and space dimension, and considering data trend. This model mainly consists of standardization system and security defending system, which achieve automatic acquisition and processing of students' learning 
behavior data by providing the management and service of six layers: perception layer, data acquisition layer, data governance layer, data computing layer, data interface layer, and business application layer. It can also conduct a correlation analysis and deep exploration of students' various learning behaviors to help students with their learning problems and then help teachers understand their students. On this basis, teachers may teach students in accordance with their aptitudes and implement individualized management.

To implement teaching big data analysis oriented to targeted service: The application of big data provides infinite possibilities for targeted teaching service and teaching data quantification. Hence, we adopt the big data technique and processed and analyzed low-frequency knowledge data, massive statistics knowledge data, and high-frequency real-time dynamic data in accordance with the individualized online teaching big data analysis oriented to targeted service. We also present the data analysis results visually for learning pre-warning, targeted resource allocation, and individualized push. Finally, we implement targeted individualized teaching and supply targeted service to achieve targeted online campus management.

To adopt modular architecture and facilitate the construction of the proposed individualized IRDC teaching mode: According to the management and service demands of teaching big data, we design an integrated management service system for an individualized IRDC online teaching mode in this study. This system serves teachers and students and can provide functions, such as data collection, data storage, data cleaning, analysis modeling, and business presentation. It contains seven centers: teaching data collection center that mainly collects teaching evaluation data, teaching assistance data, and classroom data; data preprocessing center, storage, and retrieval center, real-time computing center, mining algorithm center, and data management center that conduct automated processing and analysis of collected data; and unified application programming interface center that mainly provides unified interface to achieve data circulation and integration. This system also provides four major functions: (1) leading cockpit that teaches data analysis to achieve teaching data visualization by analyzing the quality of teaching and learning dynamic data; (2) intelligent teaching assistance that teaches supervision to establish a supervisory management system dominated by students' teaching evaluation and peer evaluation that intelligently assist teaching supervision; (3) intelligent learning assistant that assists learning to analyze students' daily learning data from student portrayal and provide learning pre-warning, students' quality evaluation, and other data application services; and (4) intelligent recommendation that aims to push individualized theme knowledge by recommending engines in accordance with students' mapping knowledge graph.

\subsection{PCA-based individualized teaching mode assessment}

First, we use PCA to reduce data dimensions for the teaching mode evaluation system. Then, we use the first four extracted principal components as the input of BP network to construct the PCA-BP network model. Finally, we verify the effectiveness of the proposed PCA-BP network model. 
1. Standardized initial data. The original sample matrix is $X(X i j) n * p$, where $n$ is the number of samples, and $\mathrm{P}$ refers to the evaluation index of each sample. We use the standardization of the mean standard deviation to standardize the original sample matrix. Formula (1) shows the specific method. $\mathrm{Xj}$ and ${ }^{\sigma_{\mathrm{j}}}$ are the mean and standard deviation of the jth evaluation index in the initial matrix. Formula (2) shows the standardized sample matrix.

$$
\begin{gathered}
\tilde{\mathrm{X}}_{\mathrm{ij}}=\left(\mathrm{x}_{\mathrm{ij}}-\mathrm{x}_{j}\right) / \sigma_{j}(\mathrm{i}=1,2, \ldots, \mathrm{n} ; \mathrm{j}=1,2, \ldots, \mathrm{n}) \\
\tilde{\mathrm{X}}\left(\tilde{\mathrm{x}}_{i j}\right)_{\mathrm{n}^{* \mathrm{p}}}=\left\{\begin{array}{l}
\tilde{\mathrm{x}}_{11}, \tilde{\mathrm{x}}_{12}, \tilde{\mathrm{x}}_{13} \ldots \tilde{\mathrm{x}}_{1 \mathrm{p}} \\
\tilde{\mathrm{x}}_{21}, \tilde{\mathrm{x}}_{22} \tilde{\mathrm{x}}_{23} \ldots \tilde{\mathrm{x}}_{2 p} \\
\ldots \ldots \ldots \ldots \ldots \ldots \ldots . . . \ldots \ldots \ldots \ldots \ldots \ldots \\
\tilde{\mathrm{x}}_{n 1}, \tilde{\mathrm{x}}_{n 2}, \tilde{\mathrm{x}}_{n 3} \ldots \tilde{\mathrm{x}}_{n p}
\end{array}\right\}
\end{gathered}
$$

2. We calculate the correlation coefficient matrix $\mathrm{R}$ of the evaluation index $\mathrm{R}$. In Formula (3), rij (i, $\mathrm{j}=1,2, \ldots, \mathrm{p})$ represents the correlation coefficient among each evaluation index.

$$
R=\tilde{X}^{\top}\left(\tilde{x}_{i j}\right) * \tilde{X}\left(\tilde{x}_{i j}\right)=\left(\mathrm{r}_{i j}\right)_{\mathrm{p}^{* \mathrm{p}}}=\left\{\begin{array}{l}
\mathrm{r}_{11}, \mathrm{r}_{12}, \mathrm{r}_{13} \ldots \mathrm{r}_{1 \mathrm{p}} \\
\mathrm{r}_{21}, \mathrm{r}_{22}, \mathrm{r}_{23} \ldots \mathrm{r}_{2 p} \\
\ldots \ldots \ldots \ldots \ldots \ldots . . . \ldots \ldots \ldots . . . \\
\mathrm{r}_{p 1}, \mathrm{r}_{p 2}, \mathrm{r}_{p 3} \ldots \mathrm{r}_{p p}
\end{array}\right\}
$$

3. We figure out the characteristic value, contribution rate, cumulative contribution rate, and feature vector of $\mathrm{R}$. We use the Jacobi method to solve $\mathrm{P}$ characteristic

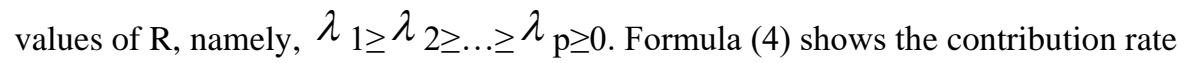
of the kth principle component, and Formula (5) shows the cumulative contribution rate of the first $\mathrm{k}$ principal components. When the cumulative contribution rate exceeds $85 \%$, we use the first k principal components for replacement. For the original $\mathrm{P}$ indices, we reserve most of the information about the original sample matrix $[5,6]$. Formula (6) shows the feature vector of $R$.

$$
\begin{aligned}
G_{k} & =\lambda_{k} / \sum_{m=1}^{p} \lambda_{m}{ }_{(\mathrm{k}<\mathrm{p})} \\
G_{1-k} & =\sum_{n=1}^{k} \lambda_{n} / \sum_{m=1}^{p} \lambda_{m} \quad(\mathrm{k}<\mathrm{p})
\end{aligned}
$$




$$
V_{1}=\left\{\begin{array}{l}
V_{12} \\
V_{21} \\
\cdot \\
V_{p 1}
\end{array}\right\}, V_{2}=\left\{\begin{array}{l}
V_{21} \\
V_{22} \\
\cdot \\
V_{p 2}
\end{array}\right\}, \ldots, V_{k}=\left\{\begin{array}{l}
V_{1 k} \\
V_{2 k} \\
\cdot \\
V_{p k}
\end{array}\right\} \begin{aligned}
& (\mathrm{k}<\mathrm{p}) \\
&
\end{aligned}
$$

4. Finally, we solve the score coefficient matrix of the principal components (new sample matrix). We multiply the principal component with the standardized sample matrix by using Formula (7) to solve a new sample matrix.

$$
f=\tilde{X}^{`}\left(\tilde{x}_{i j}\right) * V\left(V_{1}, V_{2}, \ldots, V_{k}\right)
$$

Table 1 shows the evaluation indices of the proposed individualized IRDC teaching mode. Table 2 shows the marks of individualized IRDC teaching mode indices (from $\mathrm{X} 1$ to X9) of five teachers (Teachers 1, 2, 3, 4, and 5) scored by campus/off-campus experts and peer teachers.

Table 1. Evaluation indices of the proposed individualized IRDC teaching mode

\begin{tabular}{|l|l|l|}
\hline $\begin{array}{c}\text { Teaching foundation } \\
\text { and process }\end{array}$ & \multicolumn{1}{|c|}{ Teaching application } & \multicolumn{1}{|c|}{ Teaching feedback and tracking } \\
\hline X1: Teaching material & X4: Information network resource & X7: Practical combination degree \\
\hline X2: Teaching process & X5: Specialty combination degree & X8: After-class assignment completion \\
\hline X3: Teaching method & X6: Follow-up development degree & $\begin{array}{l}\text { X9: Online answering and learning } \\
\text { guidance }\end{array}$ \\
\hline
\end{tabular}

Table 2. Summary sheet of index scores of five teachers

\begin{tabular}{|c|c|c|c|c|c|c|c|c|c|}
\hline \multirow{2}{*}{ Teacher } & \multicolumn{10}{|c|}{ Indexes } \\
\cline { 2 - 10 } & $\boldsymbol{X}_{\boldsymbol{1}}$ & $\boldsymbol{X}_{\boldsymbol{2}}$ & $\boldsymbol{X}_{\boldsymbol{3}}$ & $\boldsymbol{X}_{\boldsymbol{4}}$ & $\boldsymbol{X}_{\boldsymbol{5}}$ & $\boldsymbol{X}_{\boldsymbol{6}}$ & $\boldsymbol{X}_{\boldsymbol{7}}$ & $\boldsymbol{X}_{\boldsymbol{8}}$ & $\boldsymbol{X}_{\boldsymbol{9}}$ \\
\hline 1 & 25.12 & 31.45 & 41.52 & 44.21 & 18.47 & 14.98 & 21.26 & 6.19 & 17.87 \\
\hline 2 & 36.03 & 38.94 & 39.21 & 36.12 & 14.89 & 14.21 & 18.26 & 7.13 & 17.26 \\
\hline 3 & 19.46 & 33.86 & 41.62 & 43.51 & 20.12 & 12.67 & 17.36 & 8.65 & 18.97 \\
\hline 4 & 27.39 & 36.45 & 43.16 & 31.46 & 19.49 & 16.21 & 19.64 & 5.32 & 17.69 \\
\hline 5 & 31.89 & 41.83 & 38.97 & 37.23 & 16.86 & 14.37 & 16.43 & 5.68 & 16.12 \\
\hline
\end{tabular}

Table 3 shows the initial factor loading matrix. Information network resource X4, specialty combination degree $\mathrm{X} 5$, after-class assignment completion $\mathrm{X} 8$, and online answering and learning guidance $\mathrm{X} 9$ have high loads on the principal component $\mathrm{F} 1$, indicating that this principal component basically reflects the information of these four indices. Teaching method X3, follow-up development degree X6, and after-class assignment completion X8 have high loads on the principal component F2, indicating that this principal component basically reflects the information of these three indices. Information network resource $\mathrm{X} 4$ and practical combination degree $\mathrm{X} 7$ have high loads on the principal component $\mathrm{F} 3$, indicating that this principal component basically reflects the information of these two indices. 
Table 3. Component matrix

\begin{tabular}{|l|c|c|c|c|c|c|c|c|c|c|}
\hline \multicolumn{2}{|c|}{ Index } & $\boldsymbol{X}_{\mathbf{1}}$ & $\boldsymbol{X}_{\mathbf{2}}$ & $\boldsymbol{X}_{\mathbf{3}}$ & $\boldsymbol{X}_{\mathbf{4}}$ & $\boldsymbol{X}_{\mathbf{5}}$ & $\boldsymbol{X}_{\mathbf{6}}$ & $\boldsymbol{X}_{\mathbf{7}}$ & $\boldsymbol{X}_{\mathbf{8}}$ & $\boldsymbol{X}_{\mathbf{9}}$ \\
\hline $\begin{array}{l}\text { Principle } \\
\text { compo- } \\
\text { nent }\end{array}$ & $\mathrm{F} 1$ & -0.831 & -0.743 & -0.146 & 0.836 & 0.558 & -0.601 & 0.096 & 0.752 & 0.943 \\
\cline { 2 - 11 } & $\mathrm{F} 2$ & -0.398 & -0.527 & 0.873 & -0.169 & 0.547 & 0.749 & 0.831 & -0.532 & -0.016 \\
\cline { 2 - 11 } & $\mathrm{F} 3$ & 0.297 & -0.319 & -0.369 & 0.342 & -0.564 & 0.236 & 0.521 & -0.023 & 0.103 \\
\hline
\end{tabular}

We use the data in the component matrix to divide the corresponding characteristic value of the principal components. Then, we conduct the square root to obtain the coefficient of each index in the three principal components, namely, corresponding feature vector. Finally, we multiply the feature vector with the standardized data to gain the expression of the principal components:

$$
\begin{aligned}
& \mathrm{F} 1=-0.42 \mathrm{X} 1-0.38 \mathrm{X} 2-0.06 \mathrm{X} 3+0.43 \mathrm{X} 4+0.27 \mathrm{X} 5-0.31 \mathrm{X} 6+0.06 \mathrm{X} 7+ \\
& 0.36 \mathrm{X} 8+0.47 \mathrm{X} 9, \\
& \mathrm{~F} 2=-0.25 \mathrm{X} 1-0.36 \mathrm{X} 2-0.47 \mathrm{X} 3-0.11 \mathrm{X} 4+0.36 \mathrm{X} 5+0.42 \mathrm{X} 6+0.45 \mathrm{X} 7- \\
& 0.33 \mathrm{X} 8-0.02 \mathrm{X} 9, \\
& \mathrm{~F} 3=0.28 \mathrm{X} 1-0.31 \mathrm{X} 2-0.37 \mathrm{X} 3+0.36 \mathrm{X} 4-0.51 \mathrm{X} 5+0.26 \mathrm{X} 6+0.47 \mathrm{X} 7-0.21 \mathrm{X} 8 \\
& +0.08 \mathrm{X} 9 .
\end{aligned}
$$

Subsequently, we obtain the integrated model of the weight:

$$
\begin{aligned}
& \mathrm{F}=\frac{\lambda_{1}}{\lambda_{1}+\lambda_{2}+\lambda_{3}} \mathrm{~F}_{1}+\frac{\lambda_{2}}{\lambda_{1}+\lambda_{2}+\lambda_{3}} \mathrm{~F}_{2}+\frac{\lambda_{3}}{\lambda_{1}+\lambda_{2}+\lambda_{3}} \mathrm{~F}_{3}, \\
& \lambda_{1}=4.167, \lambda_{2}=3.086, \lambda_{3}=1.149,
\end{aligned}
$$

Thus, $\mathrm{F}=0.496 \mathrm{~F} 1+0.366 \mathrm{~F} 2+0.137 \mathrm{~F} 3$.

According to the integrated model of the principal components, we calculate the integrated principal component value and sort the five teachers for comprehensive evaluation and comparison. Table 4 shows the results.

Table 4. Principal component ranking of five teachers

\begin{tabular}{|l|c|c|c|c|c|c|c|c|}
\hline \multicolumn{1}{|c|}{ Teacher } & F1 & Rank & F2 & Rank & F3 & Rank & Comprehensive F & Rank \\
\hline Teacher 1 & 1.26 & 2 & 1.36 & 2 & 1.51 & 1 & 1.2695 & 1 \\
\hline Teacher 2 & -1.12 & 3 & -1.42 & 5 & 0.83 & 2 & -0.9536 & 4 \\
\hline Teacher 3 & 2.79 & 1 & -0.91 & 3 & -0.89 & 5 & 1.0369 & 2 \\
\hline Teacher 4 & -1.29 & 4 & 2.56 & 1 & -0.78 & 4 & 0.1645 & 3 \\
\hline Teacher 5 & -1.85 & 5 & -1.39 & 4 & -0.52 & 3 & -1.4692 & 5 \\
\hline
\end{tabular}

According to Table 4, the teachers with more in-depth understanding of the individualized IRDC teaching mode have higher scores than those with less understanding of the process. Thus, the individualized IRDC teaching mode can innovate for the online teaching mode of sports biomechanics and enhance teacher's cognition of online teaching. In this way, teachers can make the best of advantages of online teaching platform for targeted individualized teaching and utilize big data analysis accuracy to achieve interactions between teachers and students. 


\section{$4 \quad$ Teaching Example and Effect}

\subsection{Teaching example}

We chose 42 students who were admitted to the university as part of Class 1 of sports specialty as the experimental subjects and set this class as the experimental group. Then, we chose 39 students who were admitted to the university in 2019 as part of Class 2 of sports specialty as the control group. The college entrance examination result, age, and gender of the students in the two classes had no obvious statistical differences.

We introduced the individualized IRDC teaching method to the experimental group, whereas we used the traditional teaching method in the control group. The teaching program, teaching objective, class hours, and reference resources were completely consistent for the two groups. We adopted a questionnaire survey method in the research process to analyze the application effect of the individualized IRDC teaching mode based on big data in sports biomechanics. We prepared our questionnaire on the basis of five aspects: learning initiative, overall learning effect, language expression competence, scientific research thinking ability, and cooperative learning ability.

\subsection{Teaching effect}

We collected a total of 42 effective questionnaires from the experimental group, with a recovery rate of $100 \%$. Similarly, we collected a total of 39 effective questionnaires from the control group, with a recovery rate of $100 \%$. We conducted t test for scores fed back by students in the five survey items to check whether the learning effect of the experimental group was better than that of the control group. $\mathrm{T}$ value could be gained according to the following formula. If $\mathrm{p}$ value was less than 0.05 , the difference was significant. Table 5 shows the learning effect test results of the experimental and the control groups.

Table 5. Survey results of students in both groups

\begin{tabular}{|l|c|c|c|c|c|}
\hline \multicolumn{1}{|c|}{ Group } & $\begin{array}{c}\text { Learning } \\
\text { initiative }\end{array}$ & $\begin{array}{c}\text { Learning } \\
\text { effect }\end{array}$ & $\begin{array}{c}\text { Scientific research } \\
\text { thinking }\end{array}$ & $\begin{array}{c}\text { Cooperative } \\
\text { learning }\end{array}$ & $\begin{array}{c}\text { Language } \\
\text { expression }\end{array}$ \\
\hline $\begin{array}{l}\text { Experimental group } \\
(\mathrm{n}=42)\end{array}$ & $82.3 \pm 7.2 *$ & $84.1 \pm 5.4^{*}$ & $81.6 \pm 5.9^{*}$ & $83.4 \pm 6.2^{*}$ & $81.9 \pm 6.7 *$ \\
\hline Control group $(\mathrm{n}=39)$ & $76.4 \pm 8.9 *$ & $77.8 \pm 8.2 *$ & $72.6 \pm 7.4^{*}$ & $78.5 \pm 7.6^{*}$ & $76.1 \pm 8.1 *$ \\
\hline T value & 4.83 & 4.96 & 4.82 & 4.67 & 4.98 \\
\hline
\end{tabular}

Note: *means compared with the control group, $\mathrm{p}<0.05$

According to the survey results, the average performance of students in Class 1 in terms of initiative and variance was better and lower than those of the control group, respectively. For the other three aspects, namely, language expression competence, thinking ability, and end-term academic record, the students in the experimental group outperformed the students in the control group. In practice, we found that the individ- 
ualized IRDC teaching mode could improve students' initiative in sports biomechanics course and enhance their capability of independent innovation.

\section{Conclusion}

We combined the network big data and the current individualized IRDC sports biomechanics in this study. First, we analyzed the development status of the proposed individualized IRDC teaching mode. Then, we used the wireless surface EMG tester produced by NORAXON to innovate for the online teaching mode of sports biomechanics combined with the features of individualized IRDC teaching mode and enhance teacher's cognition of online teaching. With our proposed method, teachers could make the best of advantages of online teaching platform for targeted individualized teaching and utilize big data analysis accuracy to achieve interactions between teachers and students. We adopted a questionnaire survey technique to assess learning and teaching effects and draw the following conclusions:

1. The teachers who deeply analyzed the individualized IRDC teaching mode could make the most of online advantages of network platform and precisely implement individualized teaching under the guidance of big data analysis.

2. With the targeted individualized IRDC teaching, every student could be considered, and thus they could have a high learning enthusiasm.

3. Individualized IRDC teaching could push information data suitable for students by more ways. More teaching projects could enhance the interactions between teachers and students. The precise analysis of network platform could develop a rich interaction form. The enhancement of interestingness could help students easily accept knowledge.

With continues improvement of the Internet big data, the individualized IRDC teaching mode could have a wide development space. This method could provide an obviously feasible development direction for corresponding teaching reform. However, the innovation of the individualized IRDC teaching mode should be investigated further in the future.

\section{References}

[1] Warmenhoven, J., Cobley, S., Draper, C., et al. Considerations for the use of functional principal components analysis in sports biomechanics: examples from on-water rowing. Sports Biomechanics, 2017, vol. 18(3), pp. 317-341. https://doi.org/10.1080/14763141.20 $\underline{17.1392594}$

[2] Huang, J.X., Yuan, S.Y., Ding, H. Online learning and living conditions of medical college students during the COVID-19 pandemic. Chinese Journal of Medical Education, 2020, vol. 40(7), pp. 495-499.

[3] Chen, J.M. The Sports Biomechanics in Jimei University Teaching Reform for Applied Innovative Talents Training. Sports Science Research, 2017, vol. 21(3), pp. 81-84. 
[4] Knudson, D. Citation metrics of excellence in sports biomechanics research. Sports Biomech, 2019, vol. 18(3), pp. 289-296. https://doi.org/10.1080/14763141.2017.1391328

[5] Singh A. A New Approach to Teaching Biomechanics Through Active, Adaptive and Experiential Learning. Journal of Biomechanical Engineering, 2017, vol. 139(7), pp. 0710011-0710017. https://doi.org/10.1115/1.4036604

[6] Carpes, F.P., Emmanuel, S.D.R., Kunzler, M.R., et al. Using the Olympic spirit to improve teaching and learning process: the biomechanics Olympic Games. Advances in Physiology Education, 2017, vol. 41(3), pp. 436-440. https://doi.org/10.1152/advan.00027.2017

[7] Gao, B. Highly Efficient English MOOC Teaching Model Based on Frontline Education Analysis. International Journal of Emerging Technologies in Learning, 2019, vol. 14(6), pp. 138-146. https://doi.org/10.3991/ijet.v14i06.10160

[8] Li, M.L., \& Ren, Y.J. A multimedia teaching model for "sports statistics" based on arcs motivation theory. International Journal of Emerging Technologies in Learning, 2018, vol. 13(9), pp. 15-28. https://doi.org/10.3991/ijet.v13i09.8972

[9] Lee, V.R. Combining High-Speed Cameras and Stop-Motion Animation Software to Support Students' Modeling of Human Body Movement. Journal of Science Education and Technology, 2015, vol. 24, pp. 178-191. https://doi.org/10.1007/s10956-014-9521-9

[10] Fu, Y.M., Li, J. The Research and Construction of the Innovation Education Mode in the Experimental Teaching of Sports Biomechanics. Science and Technology Innovation Herald, 2015, vol. 12(27), pp. 127-128.

[11] Sun, C. Construction of 3 D human motion model under sports biomechanics. Automation \& Instrumentation, 2018, vol. 23(12), pp. 166-168.

[12] Parker, G. Postmodernist perceptions of teacher professionalism: a critique. Curriculum Journal, 2015, vol. 26(3), pp. 1-16.

\section{$7 \quad$ Authors}

Ying Liu is a Lecturer in the Teaching Department of Sports, Qufu Normal University, Shandong, China (liuying8277@163.com).

Tengqi Zhu is a Lecturer in the Teaching Department of Sports, Qufu Normal University, Shandong, China (ztengqi8277@163.com).

Article submitted 2020-07-30. Resubmitted 2020-08-29. Final acceptance 2020-08-30. Final version published as submitted by the authors. 